\title{
Skip segment Hirschsprung disease: modelling the trans-mesenteric origin of the enteric nervous system in the human colon
}

Running title: Skip segment Hirschsprung disease

Donald F Newgreen ${ }^{1^{*}}$, James M Osborne ${ }^{2}$, Dongcheng Zhang ${ }^{1}$

${ }^{1}$ Murdoch Children's Research Institute, Melbourne

${ }^{2}$ Department of Mathematics and Statistics, University of Melbourne

Contributions: Concept DFN; acquisition and analysis of data: DFN, DCZ; mathematical modelling JMO; drafting of the manuscript DFN; editing/revision of the manuscript DFN, DCZ, JMO

*Correspondence to:

Donald F Newgreen

Murdoch Children's Research Institute

Royal Children's Hospital

Parkville 3052

Victoria, Australia

Tel: 61-3-83416276

Mob: $61-448422712$

Email: $\underline{\text { don.newgreen@mcri.edu.au }}$

Summary Statement. Skip segment Hirschsprung disease in humans challenges current explanations. Mathematical modelling shows how this birth defect could develop. 


\section{ABSTRACT}

Skip segment Hirschsprung disease is a difficult to explain human enteric neuropathy where a ganglionated region lies within a region of total colonic aganglionosis.. Recently, trans-mesenteric migration was described in the mouse intestine whereby neural crest cells migrate via the mesentery across a U-shape gut loop from the midgut to the hindgut: this could explain skip segment Hirschsprung disease. To investigate this, human intestinal growth parameters were derived from published sources and correlated with enteric neural crest cell migration. These processes were then simulated using agent based mathematical models scaled to human intestinal growth. A Hirschsprung-associated slowing of migration was imposed and trans-mesenteric migration was allowed. From the developmental anatomy we conclude that trans-mesenteric migration is unlikely in normal human embryogenesis, but with a Hirschsprung-associated slowing of enteric neural crest cell migration it could occur at Carnegie stages 17 and 18 . By varying the division rate of enteric neural crest agents we could reproduce full colonisation, short segment, long segment and skip segment Hirschsprung and hypoganglionic segments.

KEY WORDS - Human colon; Innervation; Mathematical model; Cellular automata

\section{INTRODUCTION}

Hirschsprung Disease (HSCR) is a long-known (Sergi, 2015) and relatively common birth defect (East Asian: 1/3200, Caucasian: 1/5000 live births) in which the distal-most intestine lacks neurons of the enteric nervous system (ENS)(Heuckeroth, 2018; Tilghman et al., 2019). ENS neurons aggregate into numerous ganglia, hence HSCR is also known as aganglionosis (McKeown et al., 2013). The aganglionosis in about $80 \%$ of cases is confined to the rectosigmoid colon and is termed 'short segment', but 'long segment' variants occur, including total colonic agagnglionosis (TCA). The result of this is an inability to pass intestinal contents through the aganglionic segment; this produces a distension proximal to the affected region graphically termed megacolon. Current treatment is identification of the aganglionic region by biopsy (Kapur and Kennedy, 2013), surgical resection of this segment plus a safety margin into the more rostral ganglionated zone, followed by colostomy or, if possible, anastomosis of the proximal gut segment to the rectum. Without this treatment the patients suffer bouts of potentially fatal enterocolitis (Pontarelli et al., 2013), but morbidity is a problem even with surgery (Dickie et al., 2014; Rintala and Pakarinen, 2012).

The use of avian (Goldstein and Nagy, 2008) and rodent (Zimmer and Puri, 2015) models has led to an understanding of the embryological origin of HSCR. Most ENS cells are derived from vagallevel (ie. hindbrain) enteric neural crest (ENC) cells (Hutchins et al., 2018; Simkin et al., 2019). These cells migrate into the oral end of the embryonic gastrointestinal tract and colonize the rest of the gut 
to the rectum in an oral-to-anal wave of cell migration in the gut mesoderm (Young et al., 1998). A slowing or premature stoppage of this migration wave, amplified by the simultaneous growth of the gut domain within which ENC cell colonisation is occurring, explains why the segment of aganglionosis in HSCR is the distal-most segment (Landman et al., 2007). The identification of additional independent sources of ENS cells from the sacral NC (Burns and Le Douarin, 1998) and mid-trunk NC (via Schwann cell precursors) (Uesaka et al., 2015) has not led to fundamental changes to this sequence because these sources provide fewer ENS cells compared to the vagal ENC-derived cells, and cannot compensate for lack of the vagal ENC cells (Burns et al., 2000; Hearn and Newgreen, 2000). Observations of ENS formation in human embryos (Attie-Bitach et al., 1998; Fu et al., 2003; Fu et al., 2004; Wallace and Burns, 2005) are consistent with the view that the human ENS develops similarly to that in the animal models.

Despite this emphasis on the distal location of aganglionosis, a rare variant termed skip segment HSCR also occurs (Martin et al., 1979). In this form, an 'island' of ganglionated bowel of variable size and variable ganglion density occurs with aganglionic segments both oral and anal to it (Fig. 1). Combining the literature reviewed by O' Donnell and Puri (O'Donnell and Puri, 2010), Ruiz et al. (Ruiz et al., 2016) and Coe et al. (Coe et al., 2016), there have been over 30 patients with skip-like ENS defects described since 1954. Most (>90\%) skip segments have been detected in a TCA region (O'Donnell and Puri, 2010). Skip segments are typically in the caecum, the ascending colon or the transverse colon (Fig. 1). Skip segments in the more distal colon are rare (Alfawaz et al., 2017).

Conventional HSCR and skip segment HSCR are related genetically. The gene RET is the most commonly mutated gene in HSCR (Emison et al., 2010), and examination of Ret51(C618F) knock-in mice has revealed a post-caecal skip segment although most of these mice showed a simple TCA (Nishiyama et al., 2012). In addition, in humans, skip segments in a TCA context have been found in Waardenburg-Shah syndrome patients with homozygous mutation of EDNRB (Gross et al., 2015) and with hemizygous mutation of SOX10 (Ruiz et al., 2016), both known HSCR genes. Nevertheless, skip segment HSCR obviously poses a serious problem for a developmental explanation because this lesion is not accommodated by a simple curtailment of the oral-to-anal wave of ENC cell migration.

In a pioneering discussion combining evidence from wild-type and $/ s / I s$ HSCR model mice and human clinical reports, Kapur and co-workers (Kapur et al., 1995) pointed out that ENC colonisation in the gut wall was delayed in the caecum of the mouse, and a stream of ENC-derived cells extended further distally extramurally at the border of the caecum and the mesentery. After by-passing the caecum, some of these cells appeared to re-enter the colon wall distal to the caecum. This gave a transient uncolonised gap proximally including the caecal region, as well as the distal uncolonised zone. Kapur et al suggested that normally the ENC cells 'back-fill' this gap, but failure to accomplish 
this could explain caecal and juxta-caecal skip segment HSCR in humans. However this explanation is not consistent with the $40 \%$ of skip segments located in the transverse colon.

More recently another explanation has arisen (Nishiyama et al., 2012) from time-lapse observations using advanced cell imaging of ENC cell movement in mouse embryo gut in organ culture, and in static observations of mouse and human gut. At a crucial stage of intestinal colonisation, the intestine forms a U-shaped bend with the proximal midgut as one arm, joined by a short span of mesentery to the arm consisting of distal midgut (including caecum) and hindgut. As intramural ENC cells colonise the proximal arm, individual ENC cells can use the mesentery as a bridge to wander across and enter the nearby distal arm. This short-cut places these 'transmesenteric' ENC cells well ahead of the intramurally colonising cells (termed 'circumflex' ENC cells (Nishiyama et al., 2012)). Due to the 'frontal expansion' mode of colonisation (Simpson et al., 2007), these trans-mesenteric ENC cells proliferate, taking over the colonisation of more distal gut. Assuming this trans-mesenteric event occurs in vivo as it does in organ cultures, then the stage at which this can occur is probably brief in vivo since further growth and morphogenesis increases the separation of the proximal and distal intestinal arms. This and other models have been incorporated in recent reviews (Coe et al., 2016; Sehgal, 2018), and this notion of Nishiyama and colleagues (Nishiyama et al., 2012) explains the occurrence and variable position of all skip segments better than the caecal by-pass model of Kapur and colleagues (Kapur et al., 1995).

Here we ask whether this concept of trans-mesenteric origin of ENS can be applied to both normal colonic ENS formation and skip segment HSCR in humans. Direct observation and experimentation are not possible in human embryos. Therefore from on-line and published sources we derive anatomical parameters of the forming intestine and ENS in human embryos in terms of rate of development, scale and morphology. We then use computer models of ENC cell colonisation dynamics that were previously successful in animal applications (Landman et al., 2014; Landman et al., 2007; Newgreen et al., 2013) but with human temporal and anatomical parameters. From these we attempt to define the likely effect of altering the timing, location, division rate and number of the trans-mesenteric ENC cells on the ENS phenotype and the development of skip segment HSCR. Our conclusions are that trans-mesenteric migration is unlikely in normal colonisation of the human distal intestine by ENC cells, but that with a HSCR-related slowing of migration, this mechanism explains the existence and most frequent sites of skip segment disease.

\section{RESULTS AND DISCUSSION}

Likelihood and location of trans-mesenteric ENC cell migration in human embryos 
Gut morphogenesis and ENC cell colonisation in human embryos: lessons from the mouse and chick. The human embryonic mid- and hindgut undergoes extensive growth and looping (Fig. 2), as does the gut of the mouse and chick embryo. In the normal mouse, ENC cells migrate along the descending (proximal) intestinal loop at a stage when this is separated from the ENC-free ascending (distal) loop by a narrow mesentery, allowing trans-mesenteric colonisation (Nishiyama et al., 2012). By contrast, in the avian embryo, ENC cell advance occurs relatively early compared to intestinal looping (Allan and Newgreen, 1980; Southwell, 2006; Zhang et al., 2019). Uncolonised intestine is crucial for a new site of entry to become established because experiments in animal models and in mathematical models indicate that a resident ENS population suppresses the colonising ability of ENC cells arriving later (Meijers et al., 1992; Simpson et al., 2007). Thus trans-mesenteric colonisation by ENC cells does not occur in the looped chick embryo intestine because the distal intestine is already colonised by the oral-to-anal ENC cell wave.

In the developing human, like the chick, the progress of the ENC cell wavefront (see Suppl. Fig. 8 of Nishiyama et al., 2012) has advanced along the intestine before the formation of the intestinal U-shaped loop that will bring the proximal midgut arm close to the caecal and post-caecal regions of the distal intestine (Fig. 2). Thus when the separation distance makes ENC cell migration across the mesentery feasible at the sites of skip segments occur (Fig. 1), the trans-mesenteric cells would likely encounter intestine populated with ENS cells that have migrated oro-anally along the intestine. We therefore conclude that in ENS morphogenesis in the normal human embryo, transmesenteric occupation of the more distal colon is unlikely. This does not mean that human ENC cells are intrinsically incapable of this movement, rather in normal development they lack the temporal opportunity.

ENC cell colonisation in human HSCR embryos compared to rodent models. In rat and mouse embryos with a distal HSCR-like aganglionosis, the progress of the ENC migratory wave is slowed proximally even in the region that is eventually colonised (Newgreen and Hartley, 1995; Shin et al., 1999). Similar generalised slowing is likely in affected human embryos, and in this case a latent capacity of ENC cells to migrate trans-mesenterically may be unmasked.

Spatio-temporal window for trans-mesenteric migration in human embryos. The developmental anatomy of the human gut at the most common sites of skip segments offers clues as to when and where trans-mesenteric migration might occur. Note that we assume the intestinal morphology in human HSCR embryos is normal and only the progress of the ENC cell migratory wave is affected.

In the development of the mouse intestine, the caecum is relatively close to the umbilical tip of the intestinal loop whereas in the human embryonic intestine at C14-16 the caecum is positioned relatively dorsal in the ascending limb of the intestinal loop (Fig. 2). This means that in human 
embryos, trans-mesenteric crossing by ENC cells before C16 would, at the region of least separation, lodge ENC cells oral to the caecum. Since skip segments do not occur here (see Fig. 1)(O'Donnell and Puri, 2010), trans-mesenteric crossing resulting in a skip would be unlikely to occur before $\mathrm{C} 16$. On the other hand, due to growth of the intestine at and after C19 (Fig. 2, 3) the separation increases and the mesentery becomes more tortuously folded which must hinder trans-mesenteric crossing. At $\mathrm{C} 17$ and $\mathrm{C} 18$ the more proximal descending intestine is adjacent to the proximal part of the postcaecal gut (Fig. 2). Consistent with this, most skip segments have been reported in this region rather than in the more distal post-caecal intestine (Fig. 1). At this embryonic stage the distance of closest approach measured directly across the mesentery is shortest (range 300-400 $\mu \mathrm{m}$ ).

We therefore conclude that, with a slowed ENC colonisation wave, the most likely time for trans-mesenteric crossing would be stages $\mathrm{C} 17 / \mathrm{C} 18$. The length of closest approach of the proximal and distal limbs of the intestinal loop, and therefore most likely position of crossing, extends for about $1 \mathrm{~mm}$ along the caecal and post-caecal intestine at $\mathrm{C} 17 / \mathrm{C} 18$. The occurrence of a temporal and spatial window for trans-mesenteric crossing has already been described in the mouse intestine (Nishiyama et al., 2012).

\section{CA models of ENC cell colonisation reproduce conventional and skip segment HSCR}

Intestinal growth measurements in human embryos. The increase with developmental time in the length, diameter and volume of various segments of the human embryonic intestine (assuming that the gut is approximately circular in local cross-section at each point) from C14 to C21 (age postfertilization about 34 to 50 days) is given in Fig. 3. The time intervals between stages are set with stage $\mathrm{C} 14$ as starting time (nominal $t=0$ day). The area of the potential myenteric plexus is also given because this is the layer occupied by ENC cells migrating and proliferating within the gut mesoderm. This is the correlate of the 2D surface approximated in grid-format by the CA model described previously. Noteworthy is the rapid growth of the proximal (descending) midgut compared to more distal intestine, which is also observed in other species (Newgreen et al., 1996). These data are used to scale the CA model of ENC colonisation.

Skip segment HSCR can emerge in CA models of ENC cell colonisation. ENC cell number and division indirectly drives net directional motility (Barlow et al., 2008; Simpson et al., 2006; Simpson et al., 2007). HSCR mutations (Amiel et al., 2008) in ENC cells reduce their division and migration (Gianino et al., 2003; Hearn et al., 1998; Nagy and Goldstein, 2006; Wu et al., 1999; Young et al., 2001). This leads to failure of colonisation distally (ie. HSCR) if migration fails to exceed intestinal myenteric layer expansion (Newgreen et al., 1996). Previous CA models have explored a range of rates of division of ENC agents, with the focus being to produce ENC agent colonisation that 'just failed' (ie. short segment HSCR) or 'just succeeded' (Binder et al., 2015). However skip lesions occur most 
frequently in a TCA context (Coe et al., 2016; O'Donnell and Puri, 2010), which is a major failure of colonisation. This suggests a greater reduction in ENC division rate is at play.

For the CA model we derived exponential growth curves to represent the rate of human intestinal expansion (Fig. 4A). If trans-mesenteric crossing was disallowed, then HSCR of variable length could evolve depending on the values of agent movement $\mathrm{P}_{\mathrm{M}}$ and agent division $\mathrm{P}_{\mathrm{D}}$ (Suppl. Fig. S1). Then to model the ENC cell migration process (Fig. 5A, B), we imposed (Fig. 5D) a transfer of ENC agents from the descending midgut to the post-caecal gut in the spatial context of the C17/C18 stage (choice of this stage is discussed above). This was achieved by allowing cells within a specified spatial and temporal window (red in Fig. 5D) to move to sites in a region of post-caecal intestine. Once transferred to the distal arm, the agents proliferated and moved with the same parameters as agents in the originating proximal population. Note that ENS-free space in the new site is available in all directions and the CA modelled ENC agent population responds by expanding in all directions. This is likely to occur biologically because ENC cell migration directed by the availability of ENS-free space has been demonstrated experimentally in the mouse and avian intestine (Anderson et al., 2007; Burns et al., 2002; Nishiyama et al., 2012; Simpson et al., 2007). Under these conditions a skip segment may be generated and may persist (Fig. 4B).

Normal ENC agent division during colonisation evolves such that a relatively few clones at early stages contribute disproportionately to the final ENS population (Cheeseman et al., 2014). The same type of clonal inequality occurs in the skip region in the model, but the precise identities and proportions of the clonal cells in the skip segment may not be identical to that in the distal circumflex ENC population (Fig. 4C).

Varying the division of ENC agents in CA models can predict all forms of HSCR. Depending on the setting of the probability of ENC agent division $P_{D}$, outcomes emerged in the models representing the normal fully colonised ENS, conventional HSCR (distal aganglionosis), skip segment HSCR and hypoganglionic skip segment (Suppl. Fig. S1-3).

When a skip emerged because, for example, the ENC agent division setting $P_{D}$ was low to ensure a TCA context and because the distal part of the colon was not involved in the U-shaped intestinal loop, the skip segment was always in the proximal part of the post-caecal segment, in agreement with real site of skip segments (Fig. 1). When trans-mesenteric crossing was imposed with the ENC agent rate of division set relatively high, proximal and distal aganglionic zones were transient, giving a fully colonised ENS (Suppl. Fig. S2-3). By decreasing the ENC agent division rate $P_{D}$, a conventional non-skip HSCR developed via a transient skip segment (Suppl. Fig. S2,3). This waS due to the population of ENS agents derived from the trans-mesenteric agents having time to expand orally far enough to fuse with the anally directed intramural ENC agent wave. In this case 
the distal-most ENS was almost entirely composed of trans-mesenteric daughter agents as in the mouse experimental model (Nishiyama et al., 2012). However the agents failed to complete colonisation distally because, due to their low division setting, they were out-distanced by the expansion of the grid representing the growing distal gut mesoderm. Further reduction of $P_{D}$ generated skip segment HSCR (Fig. 4B, Suppl. Fig. S2), and if reduced still further the skip zone became progressively hypoganglionic to a point resembling TCA.

The timing/positon of the trans-mesenteric crossing can play an important role in the outcome of the developing gut. If the skip happens early enough it can allow the a variety of phenotypes including skip segment HSCR. On the otherhand if the crossing occurs later then the trans-mesenteric cells fail and the skip segment phenotype is transient if it appears at all (Suppl. Fig. S3). More complete presentations of the variability of outcome in these cases as $P_{M}$ and $P_{D}$ are varied is given in Suppl. Figs. S1-3.

\section{Conclusions}

How skip segment HSCR is generated has been a puzzle, and the mechanism of formation of skip segment HSCR presented here arose from recent studies of ENS formation in the normal mouse embryo, where migration of ENC cells across a mesenteric bridge from midgut to hindgut was detected (Nishiyama et al., 2012). However descriptions of the morphogenesis of the intestine and ENC colonisation presented here suggests slight but important differences in the relative timing of these two events between human and mouse embryos. Our interpretation is that, relative to intestinal looping, the progress of ENC colonisation in the human is advanced over that in the mouse. This in turn suggests that, unlike in the mouse intestine, the trans-mesenteric mode may be of little or no importance for the normal ENC-colonising wave in the human.

Despite this conclusion in the normal case, the observations presented here suggests that an HSCR-like slowing of ENC colonisation produces conditions in human embryonic intestine that would allow trans-mesenteric migration. This trans-mesenteric mechanism (Nishiyama et al., 2012) and the caecum bypass model (Kapur et al., 1995) reproduce caecal and juxta-caecal skip sites, and both models also account for the observed dearth of skip segments in the distal colon. However, this trans-mesenteric model also accounts for the most frequent sites of the skip in post-caecal gut, corresponding to the future ascending and transverse colon. In addition, the CA model shows how simply varying one numerical parameter, the probability of division of ENC cells, can simulate the full spectrum of HSCR defects such as short-segment, skip segment, and long segment such as TCA, and also patchy and hypoganglionic segments. 
We conclude that this trans-mesenteric model offers a convincing explanation for the existence, location and diversity of skip segment HSCR. We propose that skip segments are more frequent in the TCA region than is currently recognised, and this could be revealed by more closely sampling along its length (Kapur, 2016) using neuronal markers rather than conventional histology, to identify short skips, easily missed hypoganglionosis and circumferential patchy ENS distributions (Takahashi et al., 2013).

\section{MATERIALS AND METHODS}

Human embryo intestinal growth parameters. Gut measurements were derived from images in online data bases: the Virtual Human Embryo (VHE) (http://www.ehd.org/virtual-human-embryo/) (Gasser et al., 2014), 3D Atlas of Human Embryology (3DHE) (https://www.3dembryoatlas.com/) (de Bakker et al., 2016), the Multidimensional Human Embryo (http://embryo.soad.umich.edu/) and The Collection of Immunolabeled Transparent Human Embryos and Fetuses (THEF) (https://transparenthuman-embryo.com/) (Belle et al., 2017). These were supplemented with published histological and immunohistological sectional figures of ENS development (Attie-Bitach et al., 1998; Fu et al., 2003; Fu et al., 2004; Wallace and Burns, 2005) of human ENS development, reported with weekly increments. Fixed specimens were supplied by Dr T. Attie-Bitach (see ref. (Nishiyama et al., 2012)). Stated chronological ages of human embryos vary with the source; we follow the post-fertilizational ages used by O'Rahilly and Müller (O'Rahilly and Muller, 2010), focussing on Carnegie stages C14 (33-35 days) to C21 (49-52 days). A reasonable estimate of age in days at the stages considered can be made by adding 29 to the Greatest Length (GL) in $\mathrm{mm}$.

Measurements of intestinal diameter and length were made using the VHE measurement tool and with Fiji (https://imagej.nih.gov/ii/). The diameter of the future myenteric plexus layer eventually occupied by migrating ENC cells was approximated to the gut diameter, since migrating ENC cells in the midgut and hindgut are positioned close to the outer border of the intestine. This enabled the circumference to be calculated, assuming circularity in cross-section. The length multiplied by the circumference equates to the potential myenteric area that ENC cells colonise.

We made corrections to certain measurements from VHE. For example, the GL of the whole C14 embryo (VHE \#6502) from summing the sections (stated thickness $10 \mu \mathrm{m}$ ) was almost twice that of both the imaged whole specimen and the C14 average GL in O'Rahilly and Müller (2010). Since the latter dimensions are likely to be correct, the simplest explanation for this discrepancy is that the section thickness was $5 \mu \mathrm{m}$. In section images of the C15 embryo (VHE \#721) point-to-point distances derived from the online measurement tool did not match the dimensions of the same points in the whole image of the same embryo. We assumed that the scale of the imaged whole embryo was correct as it matched published dimensions for $\mathrm{C} 15$ embryos (O'Rahilly and Muller, 
2010). We therefore introduced for this specimen an ad hoc correction factor of $x 1.85$ for measurements from sections using the VHE imaging tool.

General properties of mathematical model of ENC cell colonisation. The mathematical models are based on those developed previously (Binder et al., 2012; Zhang et al., 2010; Zhang et al., 2018) involving cellular automata (CA), as reviewed by Newgreen and Landman and colleagues (Landman et al., 2014; Newgreen et al., 2013). Briefly, colonisation of the mid and hindgut by ENC cells termed ENC agents in the model - are based on occupation of the myenteric area. This is simulated in a $2 \mathrm{D}$ periodic rectangular grid representing the myenteric layer in the gut mesoderm. This $2 \mathrm{D}$ format was chosen since normal colonisation occurs in a narrow layer in the mesoderm corresponding to the future myenteric plexus. This 2D grid grows in length ( $x$-axis) by cycles of intercalary insertion of more grid spaces (Fig. 5A). Importantly, in this case the rate of growth is scaled exponentially to the growth parameters of the human intestine which were measured (see Fig. 4A). Here the domain length is given by the formula $L=a+b e^{c t}$ where parameters were chosen to fit the data in Fig. 4A ( $a=4.7390, b=0.2678$, and $c=0.2954)$.

The ENC agents occupy intestinal grid spaces, being initially distributed at the oral end. As a convention, this is the left or west end. In each timestep (of duration $d t$ ) each of these ENC agents can move to an adjacent grid space at a probability $d t P_{M}$ (Fig. 5B, note we use this rather than $P_{M}$ so we can change the timestep without changing the properties of the two). Grid adjacency is defined as those which share an edge (Fig. 5B) or those connected by a trans-mesenteric bridge (Fig. 5D). Each ENC agent can divide to produce two agents with a probability $d t P_{D}$, the daughters being placed in adjacent grid spaces (Fig. 5C). Both the direction of ENC agent movement to a new grid space and the placement of daughter agents is stochastic as this resembles normal colonisation viewed in timelapse (Young et al., 2014). An exclusion rule is imposed so that attempts by an ENC agent to move into, or place a daughter into, an occupied grid space results in that action being aborted for that cycle. Each grid space is $250 \mu \mathrm{m}$ wide and represents approximately 25 cell diameters.

A timestep of $d t=0.01$ is used and ENC agent movement of 0.01 grid spaces per time unit $\left(d t P_{m}\right.$ $=0.01$ ), approximating to 2.5 ? $\mathrm{m}$ per hour representing slower movement than the 10 ? $\mathrm{m}$ per $1 / 4$ hour, based on observations from Young and colleagues (Young et al., 2004) and Druckenbrod and Epstein (Druckenbrod and Epstein, 2005, 2007) for cells in the mouse embryos gut in organ culture, and for cells crossing trans-mesenterically (Nishiyama et al., 2012). Agent division probability $d t P_{D}$ is varied from 0.001 to 0.1 in different simulations with low probabilities reflecting low rate of division and hence a long segment HSCR condition. In the Supplementary figures we show the full range of possibilities by varying the movement probability, $d t P_{M}$, from 0.001 to 0.1 . 
The crucial point of difference between these simulations and previous models is that here some ENC agents are permitted to exit proximally and re-insert more distally ahead of the intramural wavefront. The exit and re-insertion sites are described by percentage of the gut domain length, as shown in Fig. 5D. This represents trans-mesenteric migration as described previously in the mouse (Nishiyama et al., 2012). The skip is implemented by including distal post post-caecal sites in the possible neighbour set for selected descending intestine sites. Specifically, here we consider the following cases: no skip (Suppl. Fig. S1); early skip (exiting from $20-25 \%$ and re-inserted into $70-75 \%$ of the gut; Suppl. Fig. S2); and late skip (from $40-45 \%$ and re-inserted into $90 \%-95 \%$ of the gut; Suppl. Fig. S3). This tran-mesenteric site is active between chosen times (here taken as 4 to 10 hours to approximately match $\mathrm{C} 17$ to $\mathrm{C} 18$ ).

\section{ACKNOWLEDGEMENTS}

We would like to thank Dr Raj Kapur for helpful discussions, and similarly Profs. Heather Young and Hideki Enomoto. We would also like to thank the constructors of the on-line human databases mentioned in the text, for their enormous energy and tenacity in producing these invaluable resources. 


\section{REFERENCES}

Alfawaz, A., Rojas, C., Rao, K., Sola, J., Neville, H., 2017. Skip Segment Hirschsprungs Disease:

Avoiding the Potential Pitfall of a Failed Pull-through Procedure. , EC Paediatrics pp. 25-28.

Allan, I.J., Newgreen, D.F., 1980. The origin and differentiation of enteric neurons of the intestine of the fowl embryo. Am J Anat 157, 137-154.

Amiel, J., Sproat-Emison, E., Garcia-Barcelo, M., Lantieri, F., Burzynski, G., Borrego, S., Pelet, A., Arnold, S., Miao, X., Griseri, P., Brooks, A.S., Antinolo, G., de Pontual, L., Clement-Ziza, M., Munnich, A., Kashuk, C., West, K., Wong, K.K., Lyonnet, S., Chakravarti, A., Tam, P.K., Ceccherini, I., Hofstra, R.M., Fernandez, R., Hirschsprung Disease, C., 2008. Hirschsprung disease, associated syndromes and genetics: a review. J Med Genet 45, 1-14.

Anderson, R.B., Bergner, A.J., Taniguchi, M., Fujisawa, H., Forrai, A., Robb, L., Young, H.M., 2007. Effects of different regions of the developing gut on the migration of enteric neural crest-derived cells: A role for Sema3A, but not Sema3F. Developmental Biology 305, 287-299.

Attie-Bitach, T., Abitbol, M., Gerard, M., Delezoide, A.L., Auge, J., Pelet, A., Amiel, J., Pachnis, V., Munnich, A., Lyonnet, S., Vekemans, M., 1998. Expression of the RET proto-oncogene in human embryos. Am J Med Genet 80, 481-486.

Barlow, A.J., Wallace, A.S., Thapar, N., Burns, A.J., 2008. Critical numbers of neural crest cells are required in the pathways from the neural tube to the foregut to ensure complete enteric nervous system formation. Development 135, 1681-1691.

Belle, M., Godefroy, D., Couly, G., Malone, S.A., Collier, F., Giacobini, P., Chedotal, A., 2017. Tridimensional Visualization and Analysis of Early Human Development. Cell 169, 161-173 e112. Binder, B.J., Landman, K.A., Newgreen, D.F., Ross, J.V., 2015. Incomplete penetrance: The role of stochasticity in developmental cell colonization. J Theor Biol 380, 309-314.

Binder, B.J., Landman, K.A., Newgreen, D.F., Simkin, J.E., Takahashi, Y., Zhang, D., 2012. Spatial analysis of multi-species exclusion processes: application to neural crest cell migration in the embryonic gut. Bull Math Biol 74, 474-490.

Burns, A.J., Champeval, D., Le Douarin, N.M., 2000. Sacral neural crest cells colonise aganglionic hindgut in vivo but fail to compensate for lack of enteric ganglia. Dev Biol 219, 30-43.

Burns, A.J., Delalande, J.M., Le Douarin, N.M., 2002. In ovo transplantation of enteric nervous system precursors from vagal to sacral neural crest results in extensive hindgut colonisation. Development $129,2785-2796$.

Burns, A.J., Le Douarin, N.M., 1998. The sacral neural crest contributes neurons and glia to the postumbilical gut: spatiotemporal analysis of the development of the enteric nervous system.

Development 125, 4335-4347. 
Cheeseman, B.L., Zhang, D., Binder, B.J., Newgreen, D.F., Landman, K.A., 2014. Cell lineage tracing in the developing enteric nervous system: superstars revealed by experiment and simulation. J R Soc Interface 11, 20130815.

Coe, A., Avansino, J.R., Kapur, R.P., 2016. Distal Rectal Skip-Segment Hirschsprung Disease and the Potential for False-Negative Diagnosis. Pediatr Dev Pathol 19, 123-131.

de Bakker, B.S., de Jong, K.H., Hagoort, J., de Bree, K., Besselink, C.T., de Kanter, F.E., Veldhuis, T., Bais, B., Schildmeijer, R., Ruijter, J.M., Oostra, R.J., Christoffels, V.M., Moorman, A.F., 2016. An interactive three-dimensional digital atlas and quantitative database of human development. Science 354 .

Dickie, B.H., Webb, K.M., Eradi, B., Levitt, M.A., 2014. The problematic Soave cuff in Hirschsprung disease: Manifestations and treatment. J Pediatr Surg 49, 77-81.

Druckenbrod, N.R., Epstein, M.L., 2005. The pattern of neural crest advance in the cecum and colon. Dev Biol 287, 125-133.

Druckenbrod, N.R., Epstein, M.L., 2007. Behavior of enteric neural crest-derived cells varies with respect to the migratory wavefront. Dev Dyn 236, 84-92.

Emison, E.S., Garcia-Barcelo, M., Grice, E.A., Lantieri, F., Amiel, J., Burzynski, G., Fernandez, R.M., Hao, L., Kashuk, C., West, K., Miao, X., Tam, P.K., Griseri, P., Ceccherini, I., Pelet, A., Jannot, A.S., de Pontual, L., Henrion-Caude, A., Lyonnet, S., Verheij, J.B., Hofstra, R.M., Antinolo, G., Borrego, S., McCallion, A.S., Chakravarti, A., 2010. Differential contributions of rare and common, coding and noncoding Ret mutations to multifactorial Hirschsprung disease liability. Am J Hum Genet 87, 60-74.

Fu, M., Lui, V.C., Sham, M.H., Cheung, A.N., Tam, P.K., 2003. HOXB5 expression is spatially and temporarily regulated in human embryonic gut during neural crest cell colonization and differentiation of enteric neuroblasts. Dev Dyn 228, 1-10.

Fu, M., Tam, P.K., Sham, M.H., Lui, V.C., 2004. Embryonic development of the ganglion plexuses and the concentric layer structure of human gut: a topographical study. Anat Embryol (Berl) 208, 33-41. Gasser, R.F., Cork, R.J., Stillwell, B.J., McWilliams, D.T., 2014. Rebirth of human embryology. Dev Dyn 243, 621-628.

Gianino, S., Grider, J.R., Cresswell, J., Enomoto, H., Heuckeroth, R.O., 2003. GDNF availability determines enteric neuron number by controlling precursor proliferation. Development 130, 21872198.

Goldstein, A.M., Nagy, N., 2008. A bird's eye view of enteric nervous system development: lessons from the avian embryo. Pediatr Res 64, 326-333. 
Gross, E.R., Geddes, G.C., McCarrier, J.A., Jarzembowski, J.A., Arca, M.J., 2015. Skip segment Hirschsprung disease and Waardenburg syndrome. Journal of Pediatric Surgery Case Reports 3, 143145.

Hearn, C., Newgreen, D., 2000. Lumbo-sacral neural crest contributes to the avian enteric nervous system independently of vagal neural crest. Dev Dyn 218, 525-530.

Hearn, C.J., Murphy, M., Newgreen, D., 1998. GDNF and ET-3 differentially modulate the numbers of avian enteric neural crest cells and enteric neurons in vitro. Dev Biol 197, 93-105.

Heuckeroth, R.O., 2018. Hirschsprung disease - integrating basic science and clinical medicine to improve outcomes. Nature reviews. Gastroenterology \& hepatology 15, 152-167.

Hutchins, E.J., Kunttas, E., Piacentino, M.L., Howard, A.G.A., Bronner, M., Uribe, R.A., 2018.

Migration and Diversification of the Vagal Neural Crest, Dev Biol.

Kapur, R.P., 2016. Histology of the Transition Zone in Hirschsprung Disease. Am J Surg Pathol 40, $1637-1646$.

Kapur, R.P., deSa, D.J., Luquette, M., Jaffe, R., 1995. Hypothesis: pathogenesis of skip areas in longsegment Hirschsprung's disease. Pediatr Pathol Lab Med 15, 23-37.

Kapur, R.P., Kennedy, A.J., 2013. Histopathologic delineation of the transition zone in short-segment Hirschsprung disease. Pediatr Dev Pathol 16, 252-266.

Landman, K.A., Binder, B., Newgreen, D.F., 2014. Modeling development and disease in the enteric nervous system. J Cellular Automata 9, 95-109.

Landman, K.A., Simpson, M.J., Newgreen, D.F., 2007. Mathematical and experimental insights into the development of the enteric nervous system and Hirschsprung's disease. Dev Growth Differ 49, 277-286.

Martin, L.W., Buchino, J.J., LeCoultre, C., Ballard, E.T., Neblett, W.W., 1979. Hirschsprung's disease with skip area (segmental aganglionosis). J Pediatr Surg 14, 686-687.

McKeown, S.J., Stamp, L., Hao, M.M., Young, H.M., 2013. Hirschsprung disease: a developmental disorder of the enteric nervous system. Wiley interdisciplinary reviews. Developmental biology 2, 113-129.

Meijers, J.H., van der Sanden, M.P., Tibboel, D., van der Kamp, A.W., Luider, T.M., Molenaar, J.C., 1992. Colonization characteristics of enteric neural crest cells: embryological aspects of Hirschsprung's disease. J Pediatr Surg 27, 811-814.

Nagy, N., Goldstein, A.M., 2006. Endothelin-3 regulates neural crest cell proliferation and differentiation in the hindgut enteric nervous system. Dev Biol 293, 203-217. 
Newgreen, D.F., Dufour, S., Howard, M.J., Landman, K.A., 2013. Simple rules for a "simple" nervous system? Molecular and biomathematical approaches to enteric nervous system formation and malformation. Dev Biol 382, 305-319.

Newgreen, D.F., Hartley, L., 1995. Extracellular matrix and adhesive molecules in the early development of the gut and its innervation in normal and spotting lethal rat embryos. Acta Anat (Basel) 154, 243-260.

Newgreen, D.F., Southwell, B., Hartley, L., Allan, I.J., 1996. Migration of enteric neural crest cells in relation to growth of the gut in avian embryos. Acta Anat (Basel) 157, 105-115.

Nishiyama, C., Uesaka, T., Manabe, T., Yonekura, Y., Nagasawa, T., Newgreen, D.F., Young, H.M.,

Enomoto, H., 2012. Trans-mesenteric neural crest cells are the principal source of the colonic enteric nervous system. Nat Neurosci 15, 1211-1218.

O'Donnell, A.M., Puri, P., 2010. Skip segment Hirschsprung's disease: a systematic review. Pediatr Surg Int 26, 1065-1069.

O'Rahilly, R., Muller, F., 2010. Developmental stages in human embryos: revised and new measurements. Cells Tissues Organs 192, 73-84.

Pontarelli, E.M., Ford, H.R., Gayer, C.P., 2013. Recent developments in Hirschsprung's-associated enterocolitis. Current gastroenterology reports 15, 340.

Rintala, R.J., Pakarinen, M.P., 2012. Long-term outcomes of Hirschsprung's disease. Semin Pediatr Surg 21, 336-343.

Ruiz, S.L., Hurtado, C.M., Fernandes, R.C., Ossorio, J.I.S., Nunez, R.N., 2016. Skip segment Hirschsprung's disease in a patient with Shah-Waardenburg Syndrome. Journal of Pediatric Surgery Case Reports 15, 44-47.

Sehgal, R., 2018. Neural crest cells and the mesentery., Mesentery Peritoneum 2018. map.amegroups.com.

Sergi, C., 2015. Hirschsprung's disease: Historical notes and pathological diagnosis on the occasion of the 100(th) anniversary of Dr. Harald Hirschsprung's death. World journal of clinical pediatrics 4, 120-125.

Shin, M.K., Levorse, J.M., Ingram, R.S., Tilghman, S.M., 1999. The temporal requirement for endothelin receptor-B signalling during neural crest development. Nature 402, 496-501.

Simkin, J.E., Zhang, D., Stamp, L.A., Newgreen, D.F., 2019. Fine scale differences within the vagal neural crest for enteric nervous system formation. Dev Biol 446, 22-33.

Simpson, M.J., Landman, K.A., Hughes, B.D., F., N.D., 2006. Looking inside an invasion wave of cells using continuum models: proliferation is the key. J Theor Biol 243, 343-360. 
Simpson, M.J., Zhang, D.C., Mariani, M., Landman, K.A., Newgreen, D.F., 2007. Cell proliferation drives neural crest cell invasion of the intestine. Dev Biol 302, 553-568.

Southwell, B.R., 2006. Staging of intestinal development in the chick embryo. Anat Rec A Discov Mol Cell Evol Biol 288, 909-920.

Takahashi, T., Kato, Y., Okazaki, T., Koga, H., Lane, G.J., 2013. Patchy innervation confirmed in pullthrough bowel with normal conventional biopsy results in Hirschsprung's disease - the benefit of circumferential biopsying. Hepatogastroenterology 60, 1014-1017.

Tilghman, J.M., Ling, A.Y., Turner, T.N., Sosa, M.X., Krumm, N., Chatterjee, S., Kapoor, A., Coe, B.P., Nguyen, K.-D.H., Gupta, N., Gabriel, S., Eichler, E.E., Berrios, C., Chakravarti, A., 2019. Molecular Genetic Anatomy and Risk Profile of Hirschsprung's Disease. New England Journal of Medicine 380, 1421-1432.

Uesaka, T., Nagashimada, M., Enomoto, H., 2015. Neuronal Differentiation in Schwann Cell Lineage Underlies Postnatal Neurogenesis in the Enteric Nervous System. J Neurosci 35, 9879-9888.

Wallace, A.S., Burns, A.J., 2005. Development of the enteric nervous system, smooth muscle and interstitial cells of Cajal in the human gastrointestinal tract. Cell Tissue Res 319, 367-382.

Wu, J.J., Chen, J.X., Rothman, T.P., Gershon, M.D., 1999. Inhibition of in vitro enteric neuronal development by endothelin-3: mediation by endothelin B receptors. Development 126, 1161-1173. Young, H.M., Bergner, A.J., Anderson, R.B., Enomoto, H., Milbrandt, J., Newgreen, D.F., Whitington, P.M., 2004. Dynamics of neural crest-derived cell migration in the embryonic mouse gut. Dev Biol 270, 455-473.

Young, H.M., Bergner, A.J., Simpson, M.J., McKeown, S.J., Hao, M.M., Anderson, C.R., Enomoto, H., 2014. Colonizing while migrating: how do individual enteric neural crest cells behave? BMC Biol 12, 23.

Young, H.M., Hearn, C.J., Ciampoli, D., Southwell, B.R., Brunet, J.F., Newgreen, D.F., 1998. A single rostrocaudal colonization of the rodent intestine by enteric neuron precursors is revealed by the expression of Phox $2 \mathrm{~b}$, Ret, and p75 and by explants grown under the kidney capsule or in organ culture. Dev Biol 202, 67-84.

Young, H.M., Hearn, C.J., Farlie, P.G., Canty, A.J., Thomas, P.Q., Newgreen, D.F., 2001. GDNF is a chemoattractant for enteric neural cells. Dev Biol 229, 503-516.

Zhang, D., Brinas, I.M., Binder, B.J., Landman, K.A., Newgreen, D.F., 2010. Neural crest regionalisation for enteric nervous system formation: implications for Hirschsprung's disease and stem cell therapy. Dev Biol 339, 280-294. 
bioRxiv preprint doi: https://doi.org/10.1101/2019.12.22.886606; this version posted December 23, 2019. The copyright holder for this preprint (which was not certified by peer review) is the author/funder, who has granted bioRxiv a license to display the preprint in perpetuity. It is made available under aCC-BY-NC-ND 4.0 International license.

Zhang, D., Osborne, J.M., Abu-Bonsrah, K.D., Cheeseman, B.L., Landman, K.A., Jurkowicz, B., Newgreen, D.F., 2018. Stochastic clonal expansion of "superstars" enhances the reserve capacity of enteric nervous system precursor cells. Dev Biol 444 Suppl 1, S287-S296.

Zhang, D., Rollo, B.N., Nagy, N., Stamp, L., Newgreen, D.F., 2019. The enteric neural crest progressively loses capacity to form enteric nervous system. Dev Biol 446, 34-42.

Zimmer, J., Puri, P., 2015. Knockout mouse models of Hirschsprung's disease. Pediatr Surg Int 31, 787-794. 


\section{FIGURE LEGENDS}

Fig. 1. Locations and frequencies of skip segments in human large bowel. Ganglionated regions are indicated by black dots. The diagram is not indicative of the area of the ganglionated regions nor of ganglion cell density. From O’Donnell and Puri, 2010.

Fig. 2. Sketches of intestine morphogenesis of the human embryo. These drawings are based on sections (VHE), reconstructions (3DHE) and wholemount images (THEF). The red arrow indicates the front of the ENC cell colonisation wave in normal development, estimated from Attie-Bitach et al. 1998; Fu et al., 2003, 2004; Wallace and Burns 2005; Nishiyama et al., 2012. The pink overlay area represents the trans-mesenteric insertion site in the post-caecal colon.

Fig. 3. Human embryo intestinal growth parameters from C14 to C21. C14 (about 34 days postfertilization) is set at 0 days and C21 (about 50 days post-fertilization) is set at about 16 days. Key: Gut from bile duct and midgut to tip of loop= duo/desc $\mathrm{mg}$. Midgut from tip of loop to mid-caecum= asc $\mathrm{mg}$. Distal gut from caecum to cloaca=post-caecal. Tubular caecum (after $\mathrm{C20}$ )=caecum.

Fig. 4. Modelling of skip segment formation. A. The growth parameters of the intestine can be approximated accurately by exponential curves. B. Single simulation of the time course of colonisation of the growing intestine with low rate of division $P_{D}$ to cause TCA with superimposed trans-mesenteric crossing. Here the ENC agent $P_{D}$ and the rate of intestinal expansion are balanced such that the lengths of the aganglionic zones flanking the skip segment do not change.

Developmental time $=x$-axis, gut length $=y$-axis. C. Plotting of ENC agent clones indicates dominance of a few clones (see Cheeseman et al., 2014) in both the proximal colonised segment and in the skip segment, but the relative contribution of clones is not identical in the two segments.

Fig. 5. Scheme for modelling circumflex and trans-mesenteric ENC agent colonisation. A. The gut mesoderm layer (grey, gridded) increases in length at each timestep by choosing at random one grid site (black) in each row to duplicate, intercalating the new site into the row. B. At probability $\mathrm{dtP}_{\mathrm{M}}$ each ENC agent (coloured circles) may move to any one of four adjacent sites (stars) chosen at random. Double occupancy is prevented by the second occupant's move being aborted. C. At probability $d t P_{D}$ each ENC agent (coloured circles) may divide, the two daughter agents (dotted circles) being placed randomly (arrows) north/south or east/west of the original position. Double occupancy is prevented by the second occupant's division being aborted. D. Concept of CA model 
of severe HSCR (TCA) with trans-mesenteric crossing. Gut myenteric layer is shown in dark grey.

This gut layer expands in length according to Fig. 5A. Circumflex ENS agents (black dots) colonize oro-anally in this gut layer (black arrow). Conditions of ENC agent division and migration versus gut expansion are used such that these ENC agents do not colonise past the caecum, equivalent to TCA. Some ENC agents are translocated (in red) from descending midgut to distal to caecum, by including post caecal sites in the neighbours of the selected cells, to model the trans-mesenteric migration process. These agents then colonise the post-caecal gut in all directions (red arrows) with the same division and motility parameters as the proximal ENC agents. 


\section{transverse colon}

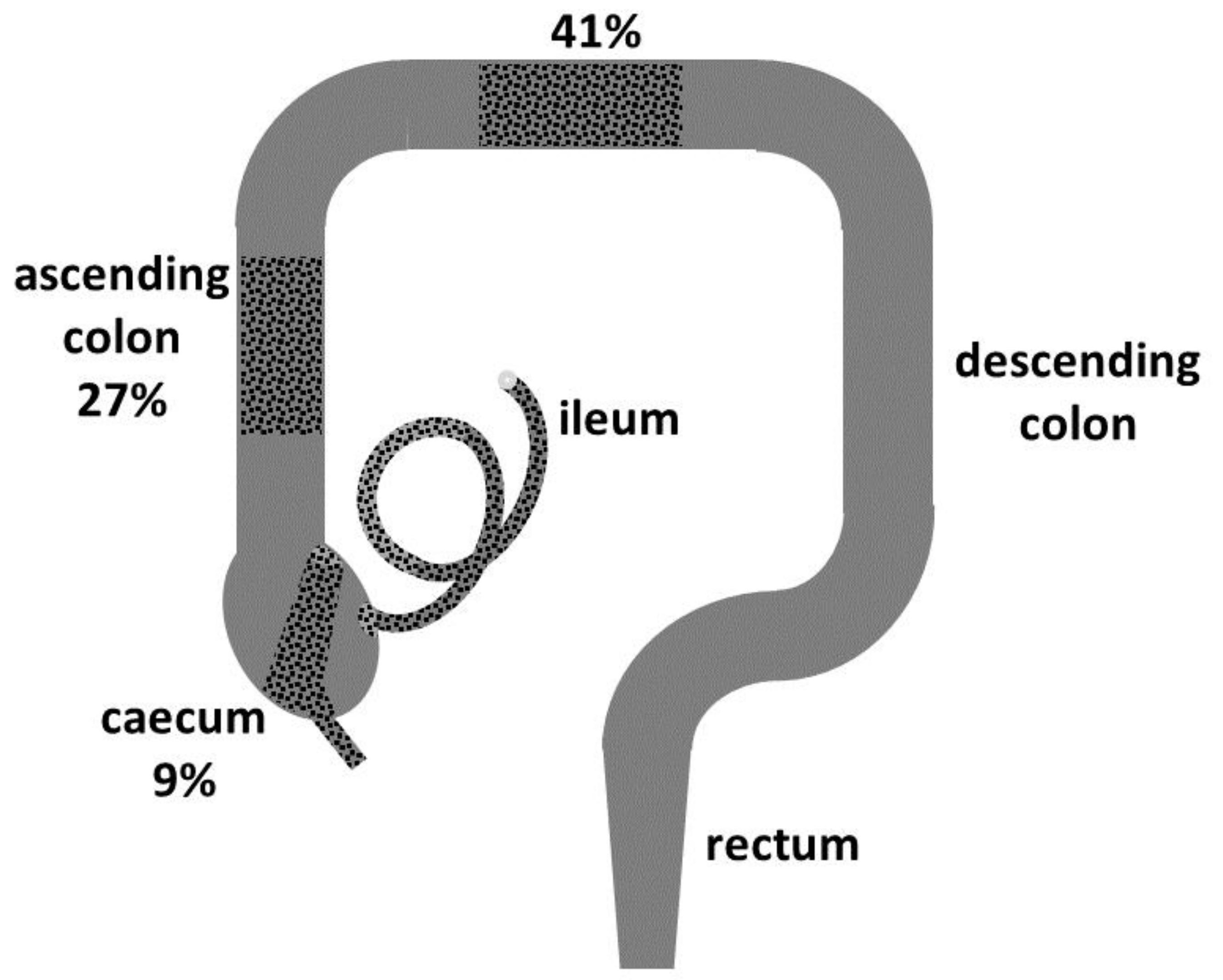


C14
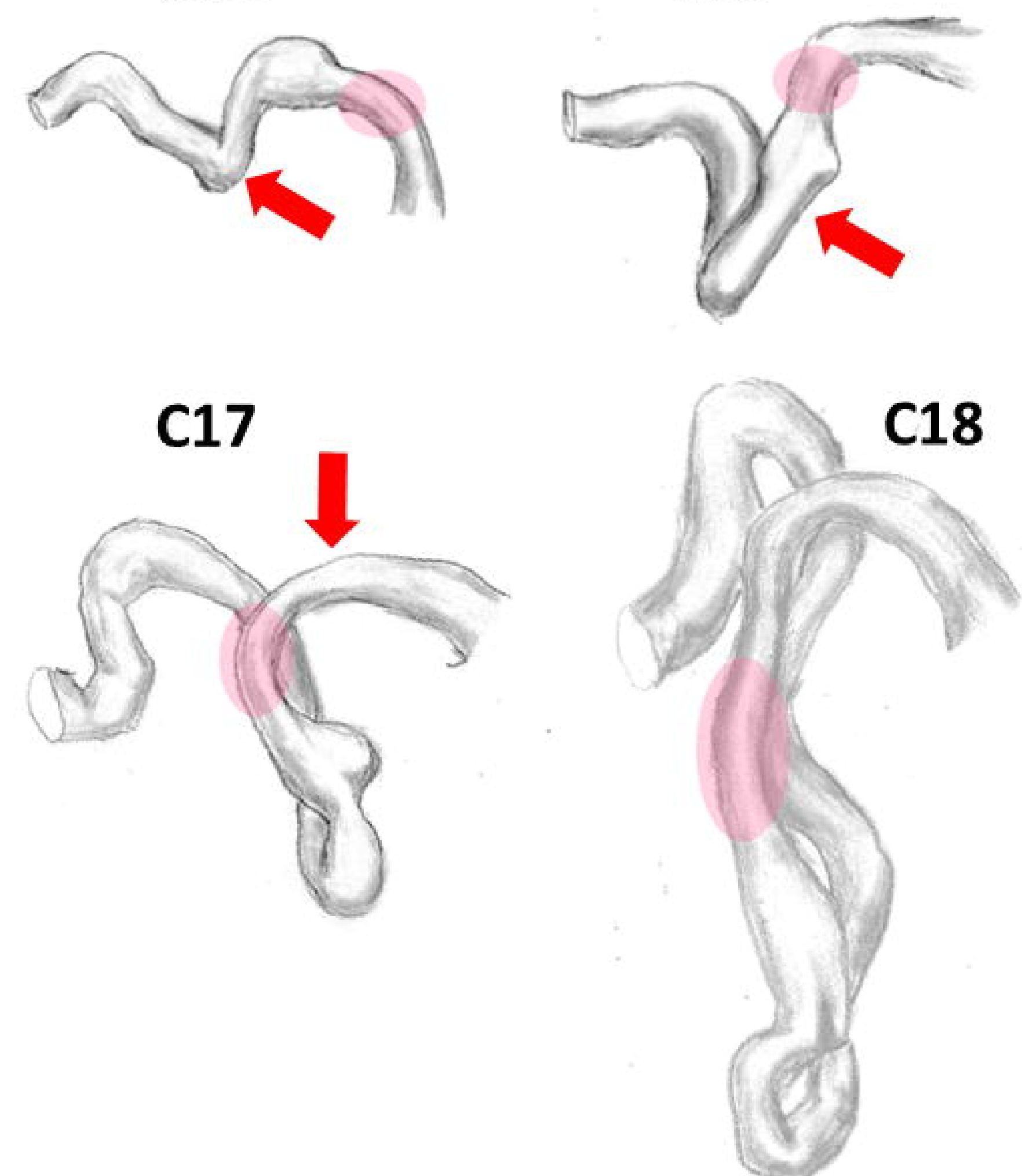

bioRxiv preprint doi: https://doi.org/10.1101/2019.12.22.886606; this version posted December 23, 2019. The copyright holder for this preprint available under aCC-BY-NC-ND 4.0 International license.
C15

C16

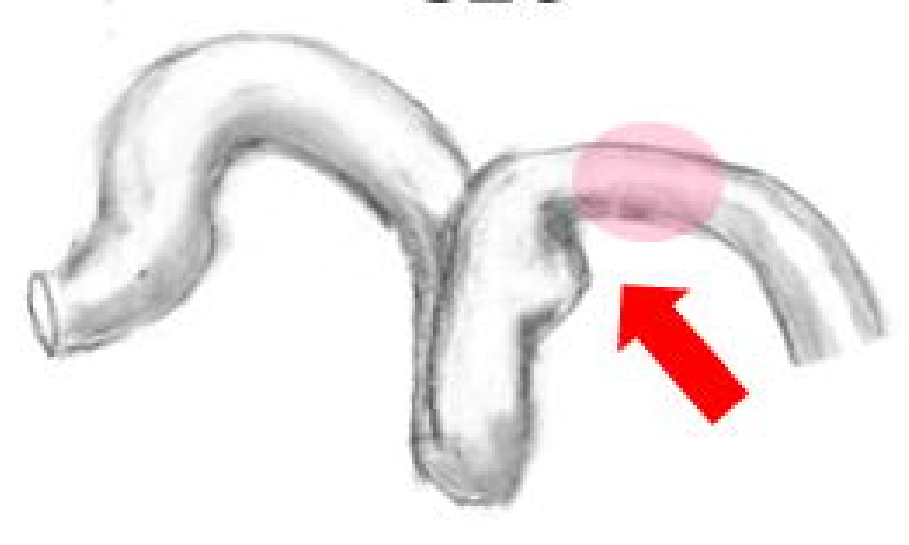

C19
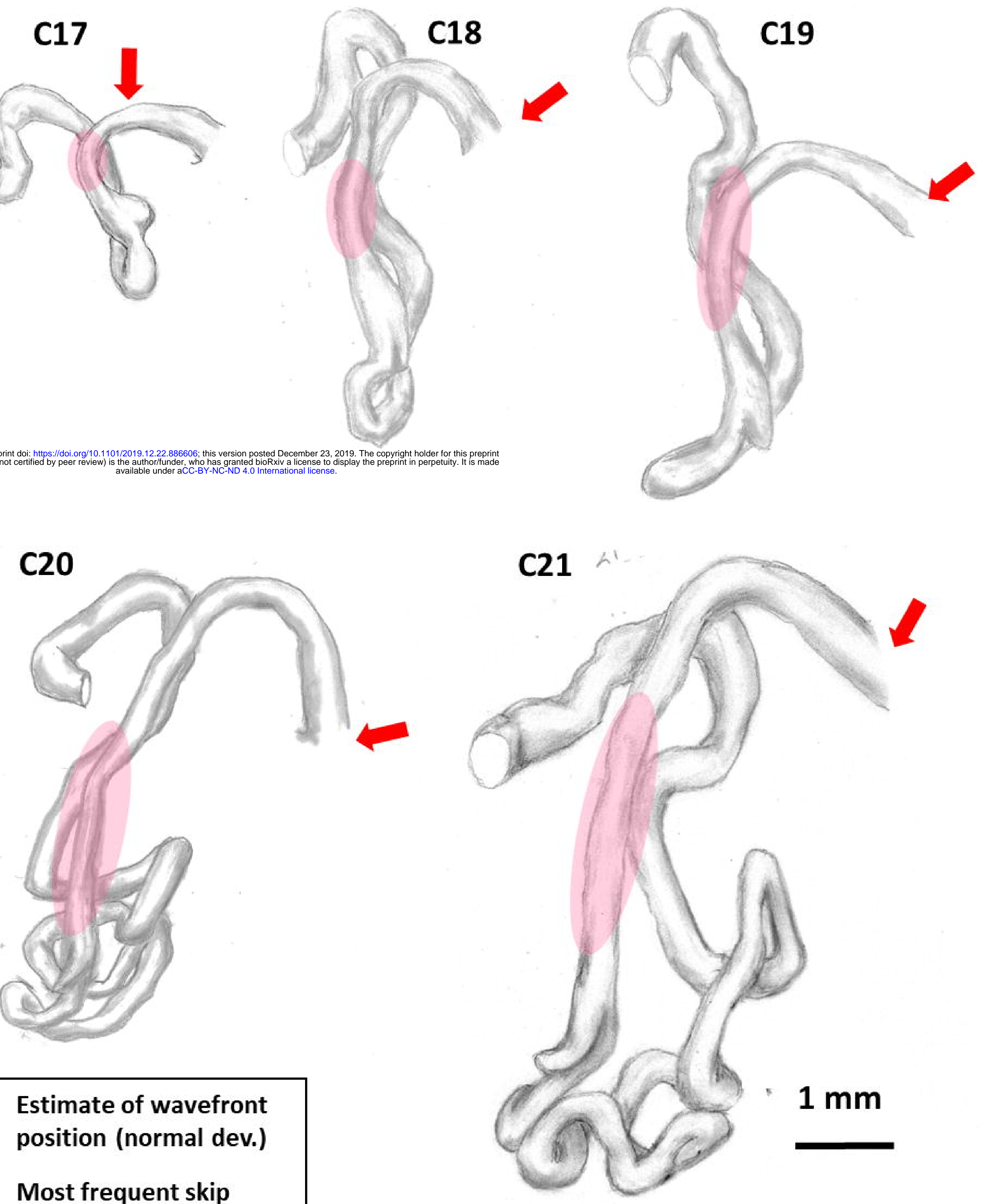

Most frequent skip location 


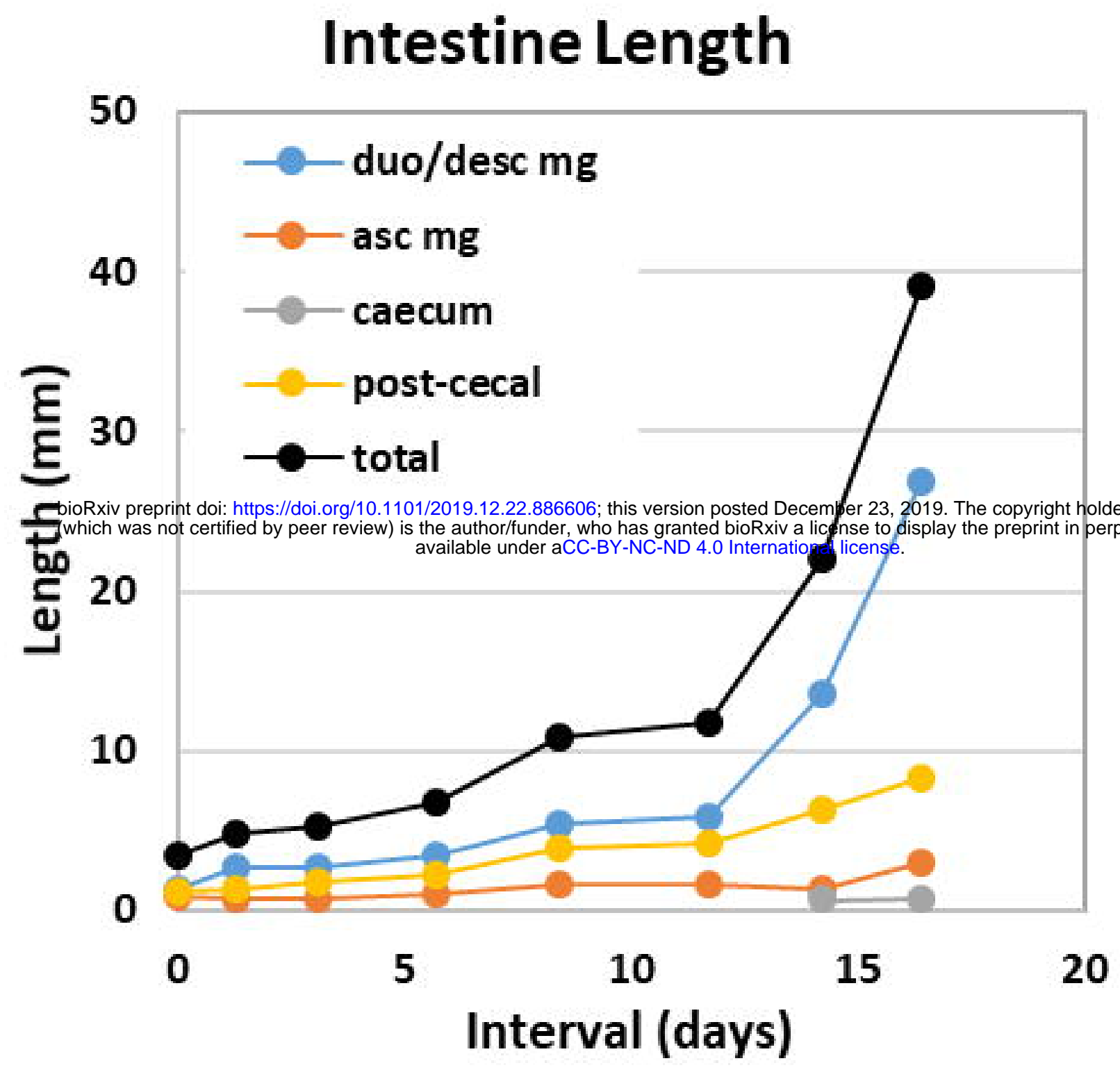

Intestine Volume

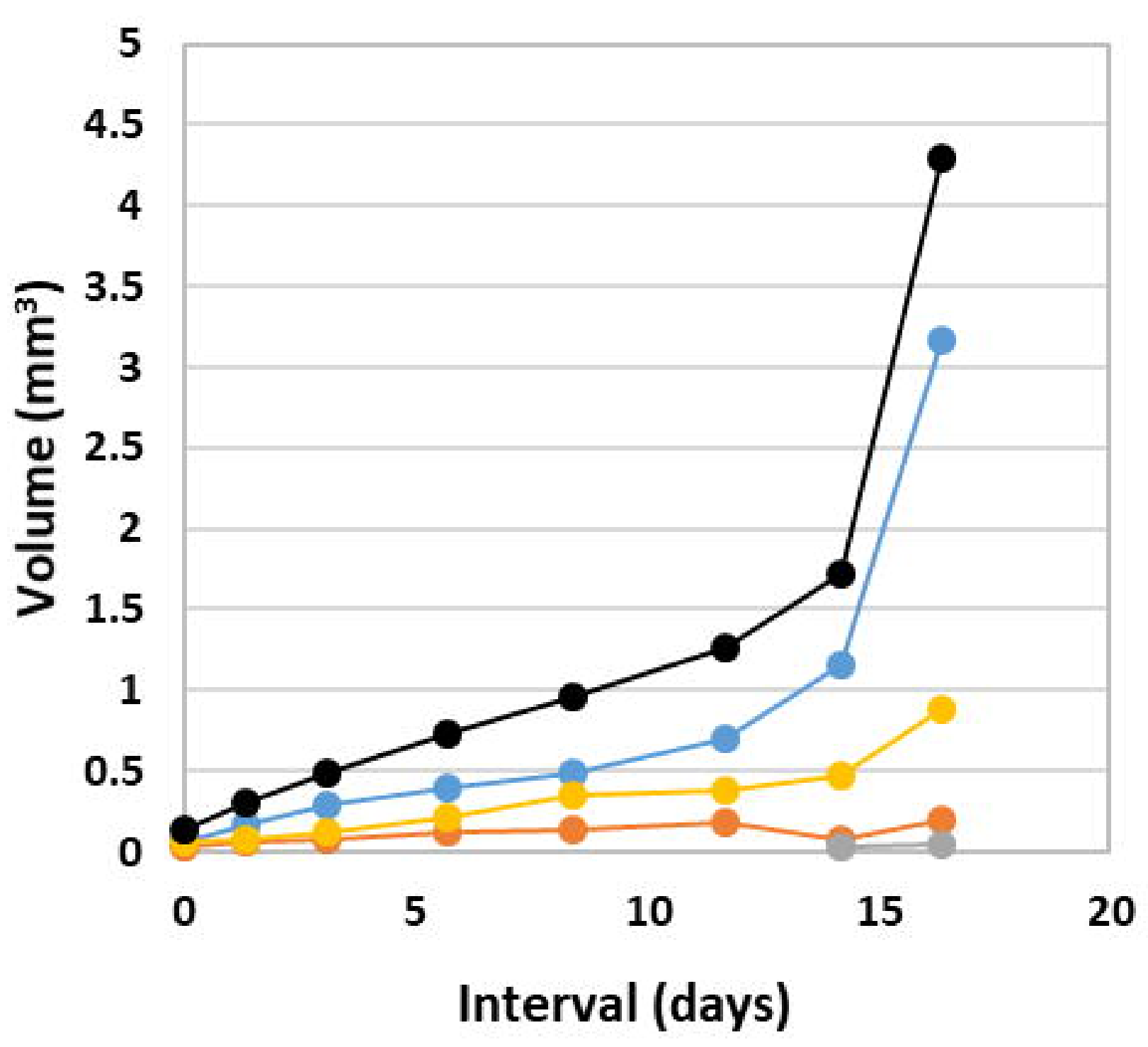

\section{Intestine Diameter}

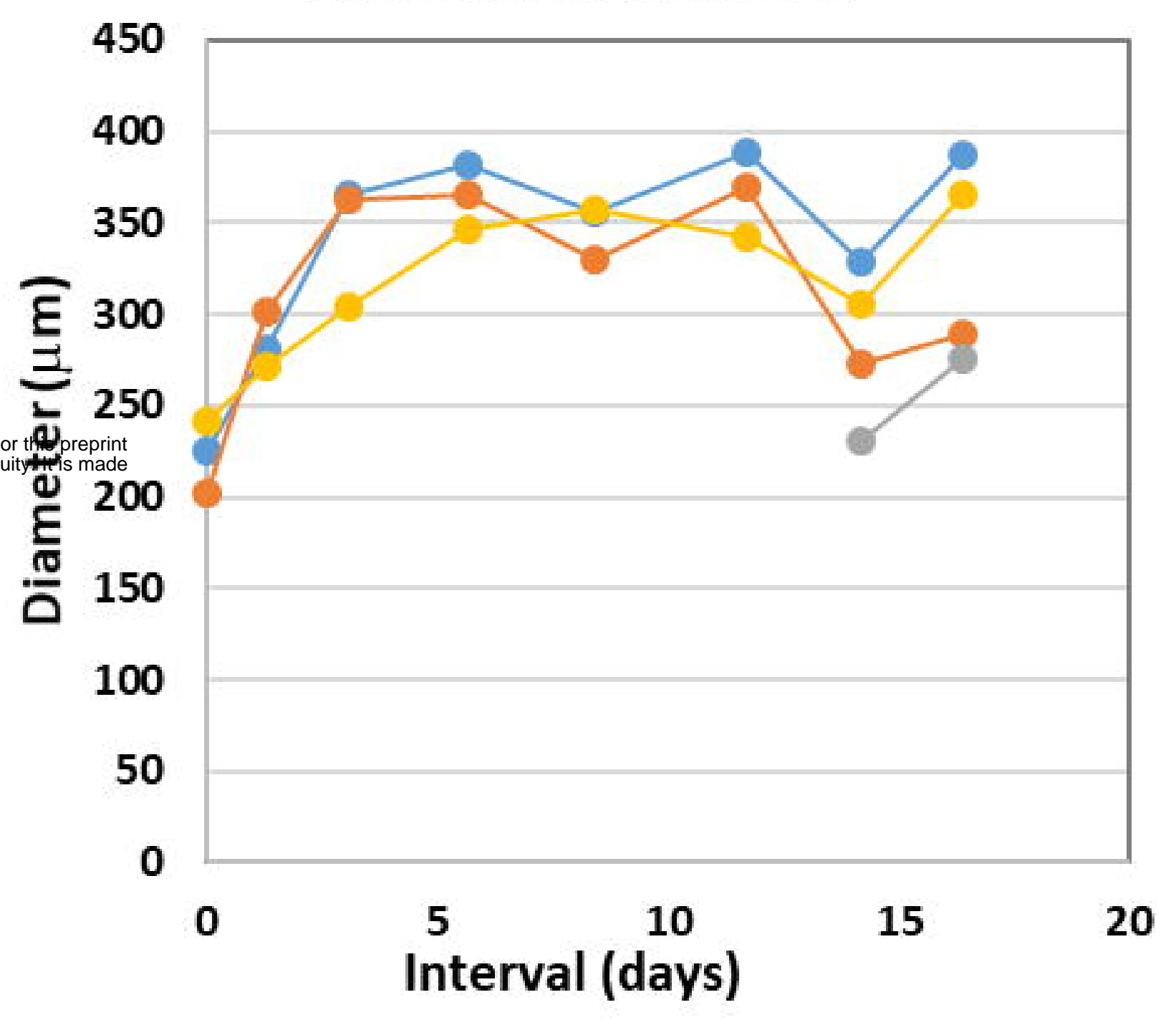

\section{Myenteric Area}

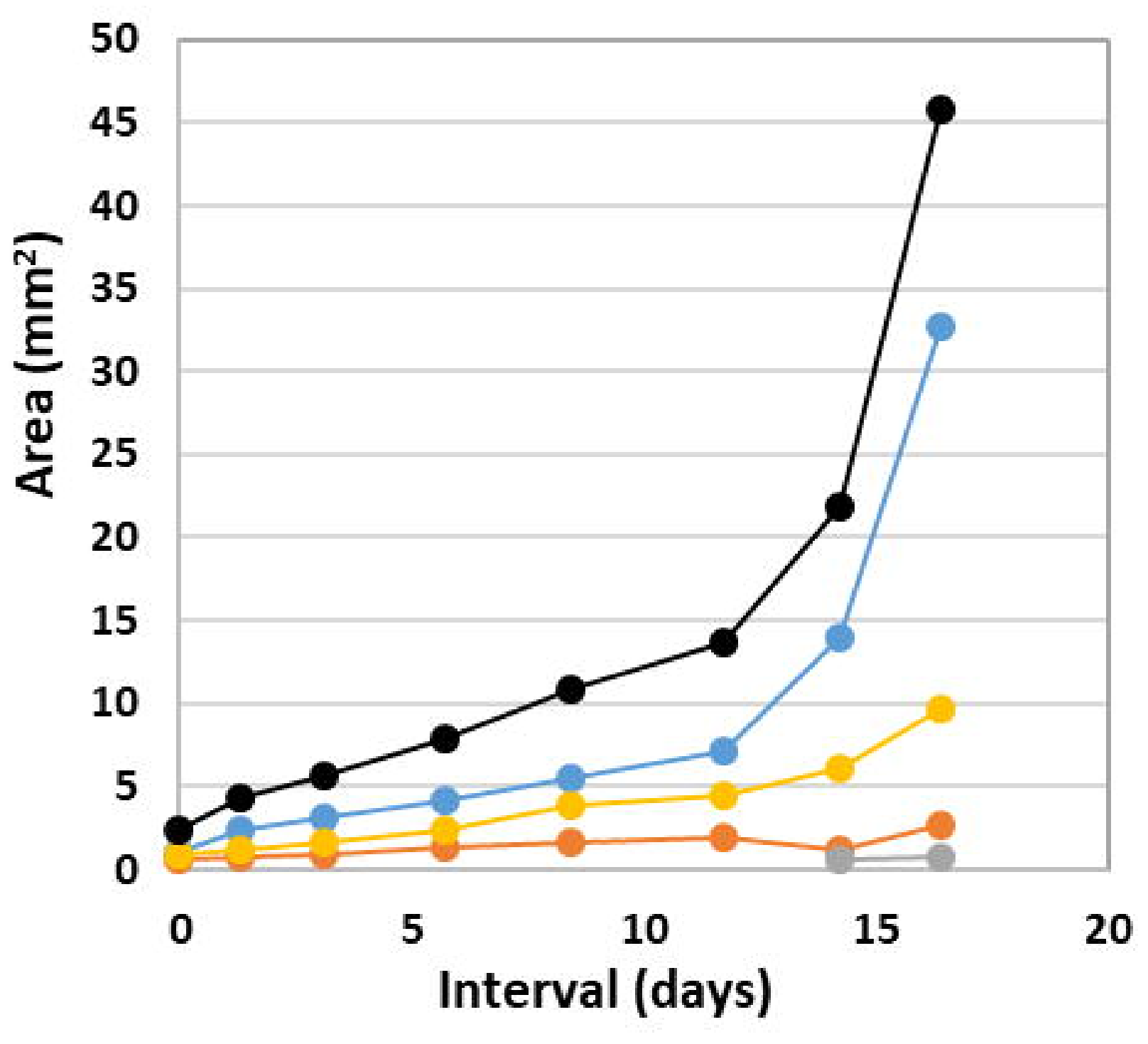




\section{A. Matching of exponential}

curves (dotted lines) to

B. ENS cell colonisation with low proliferation (TCA) with trans-mesenteric

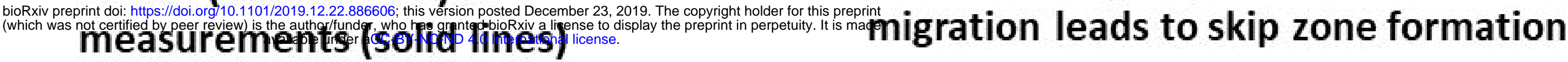
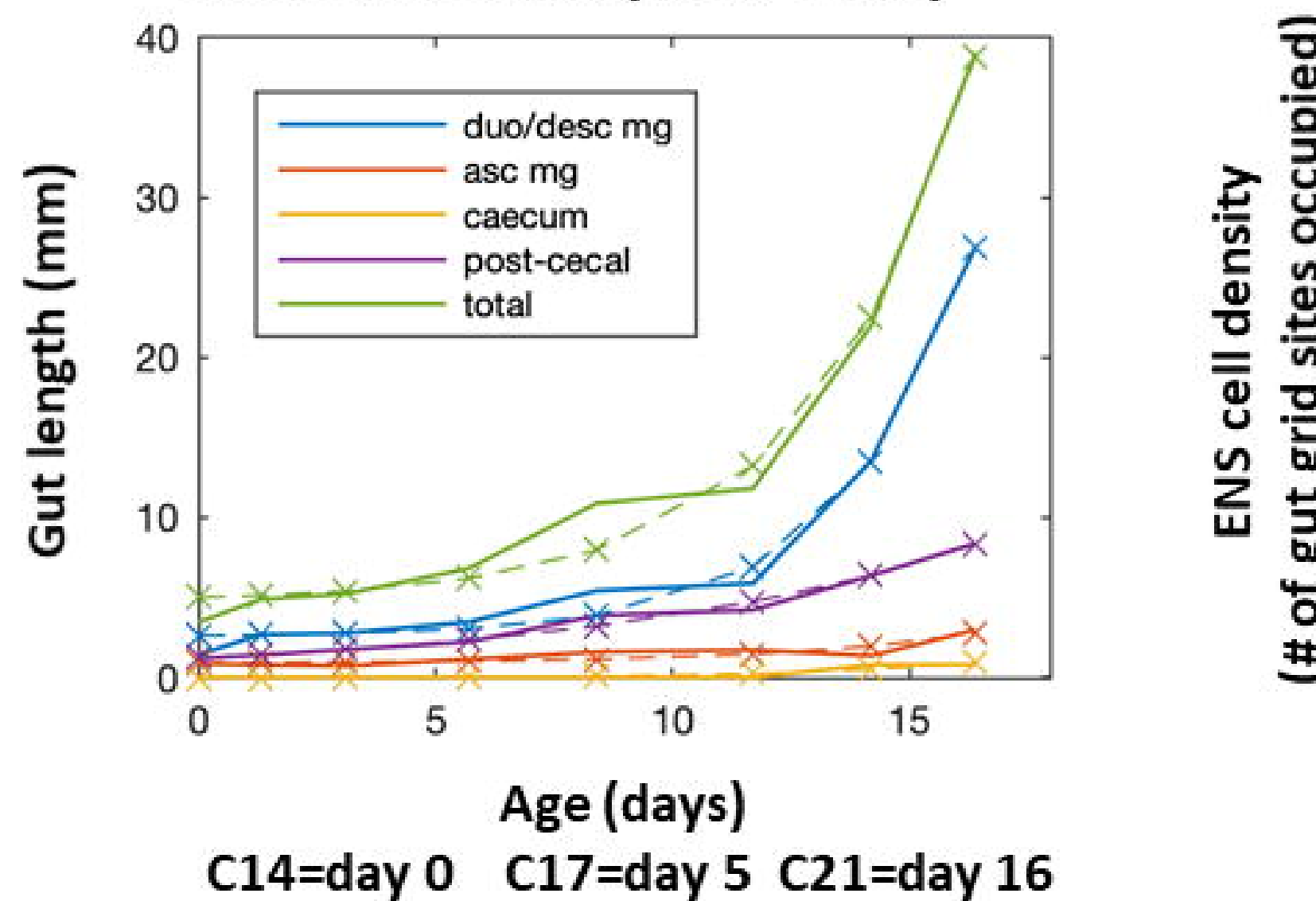

C14=day 0 C17=day 5 C21=day 16

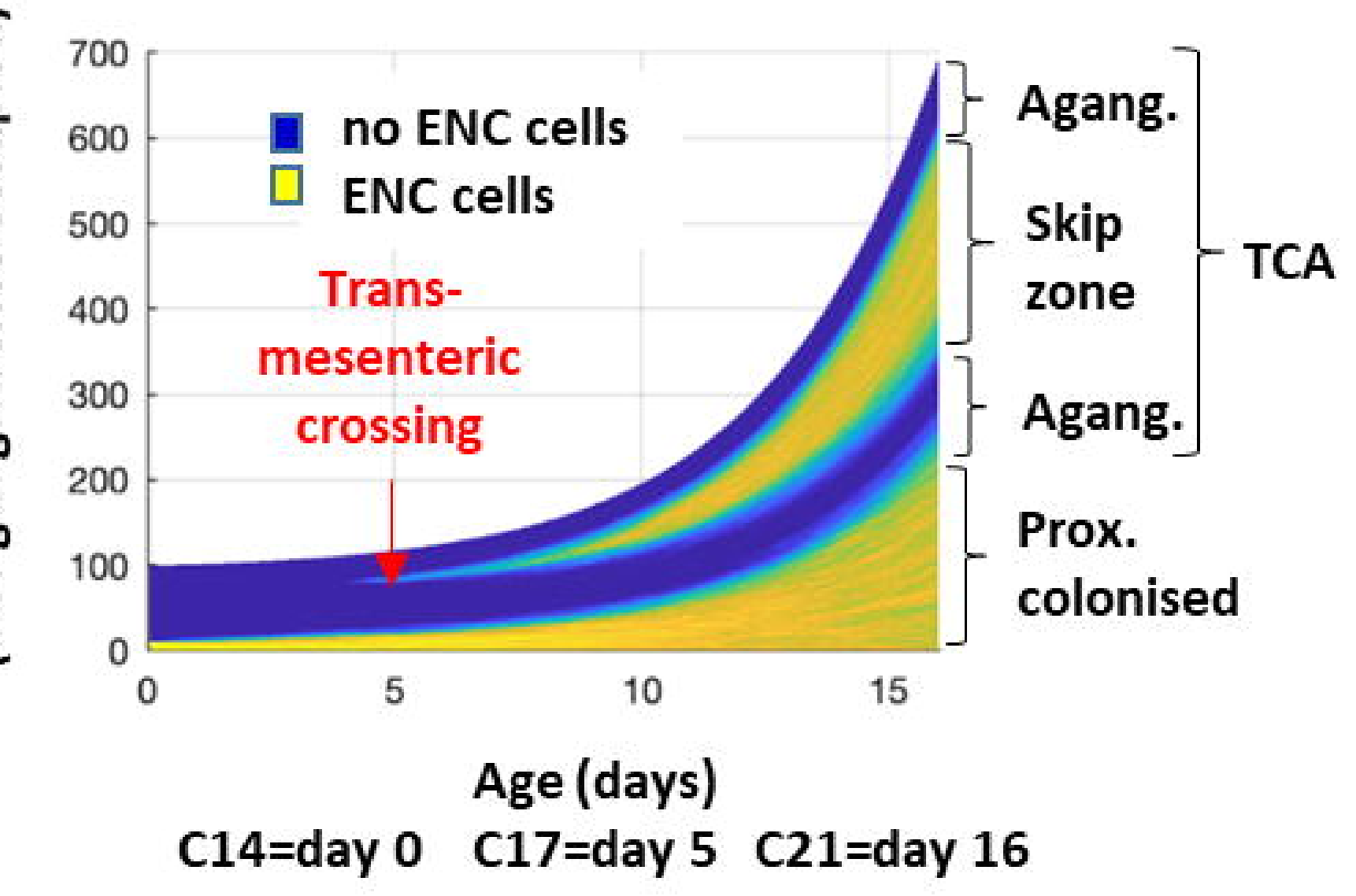

C. Colonisation by ENS cells with low proliferation with trans-mesenteric migration

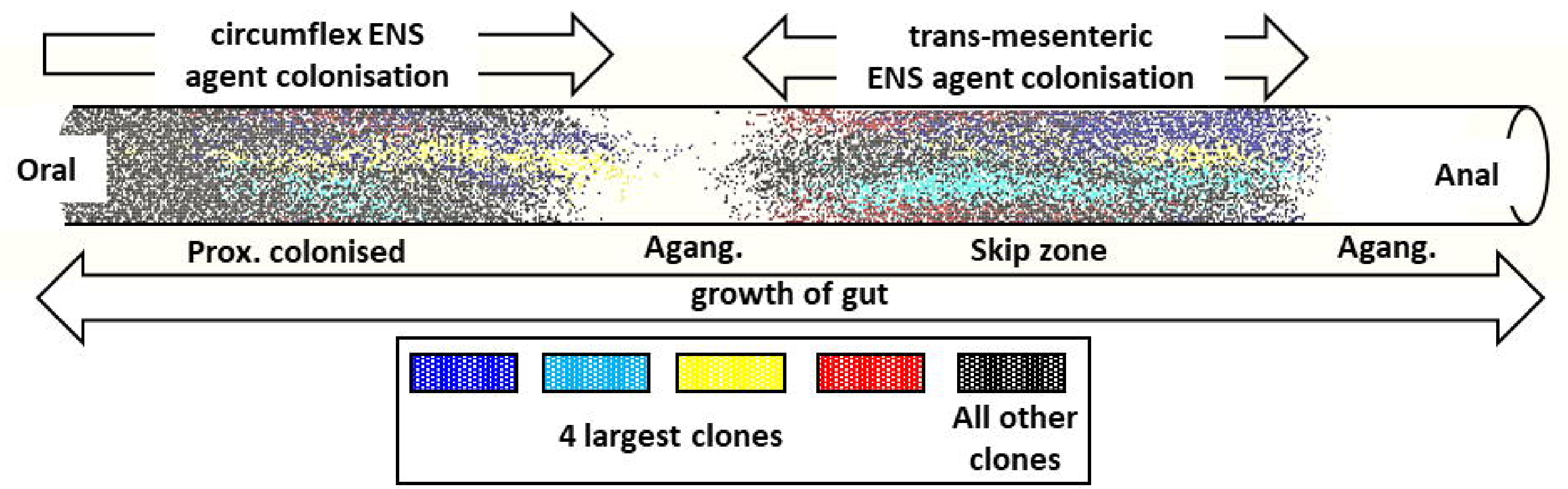




\section{A. Gut mesoderm site growth rule}

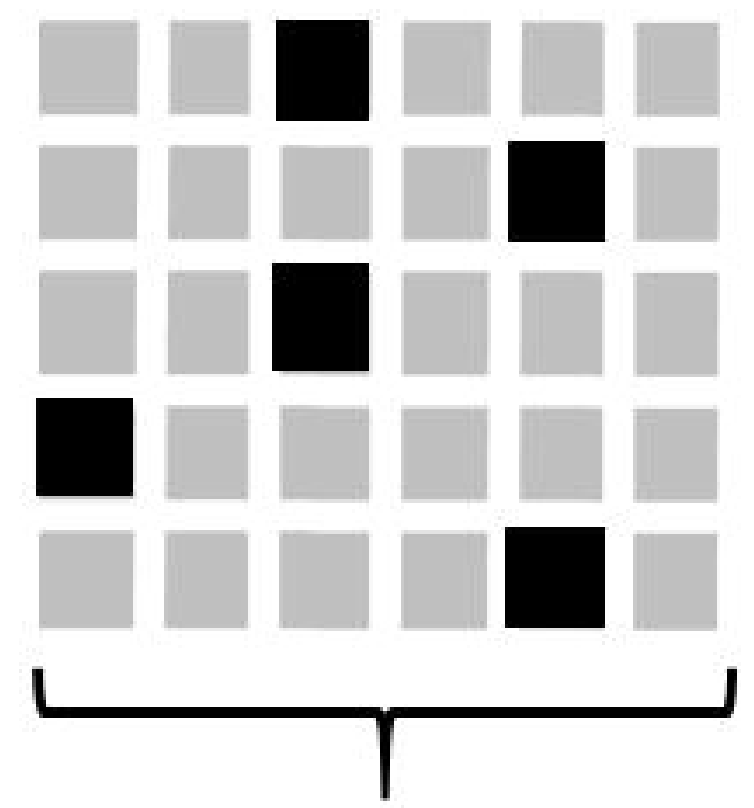

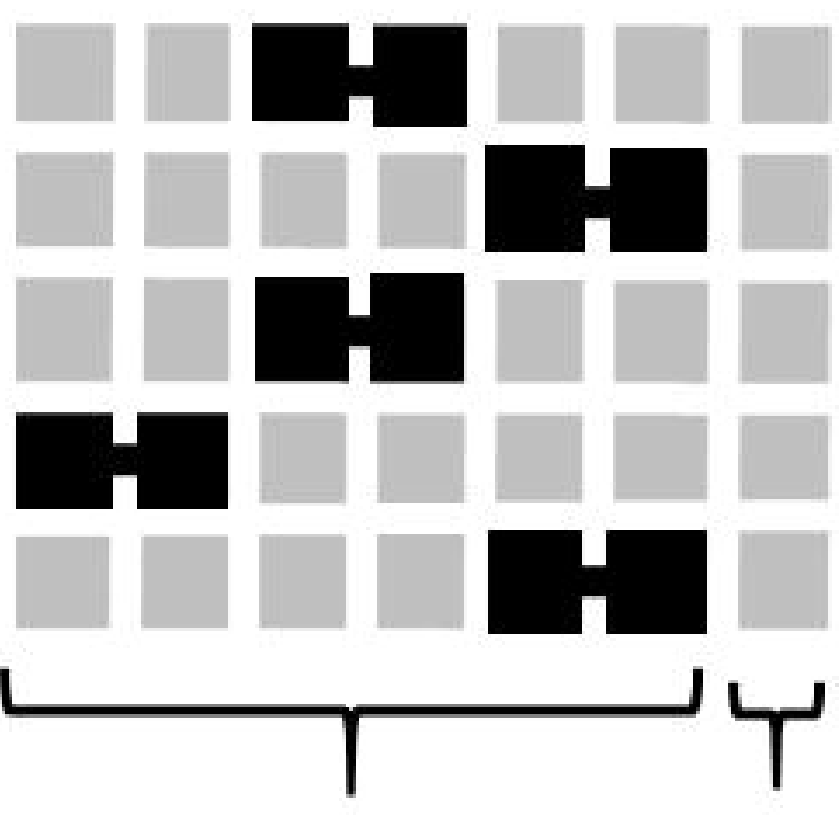

B. NC agent motility rule

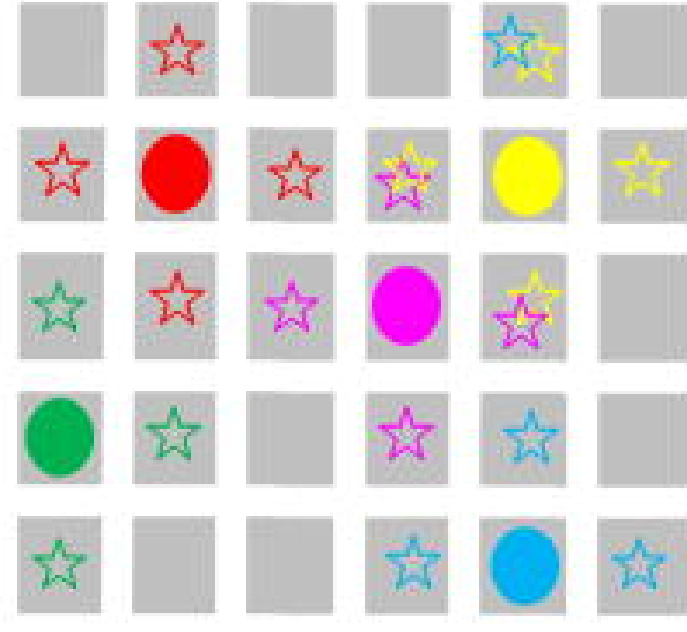

C. NC agent proliferation rule

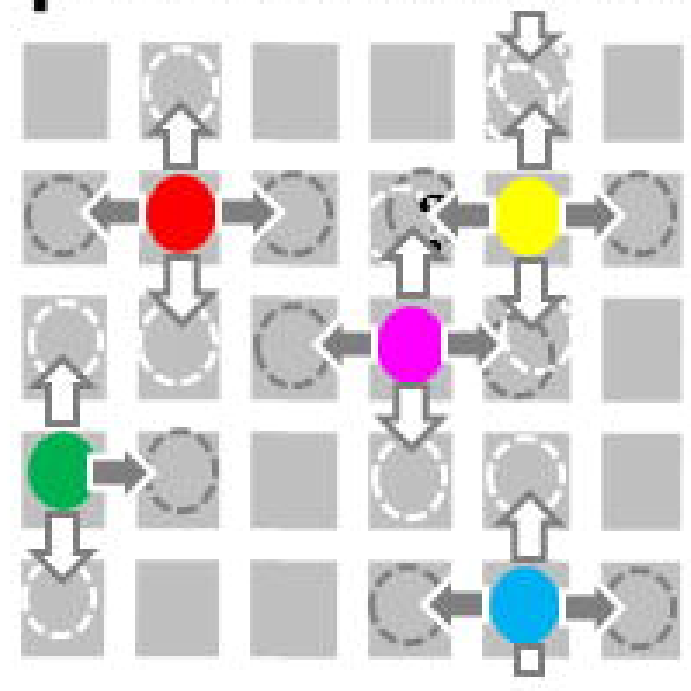

D. Trans-mesenteric transfer

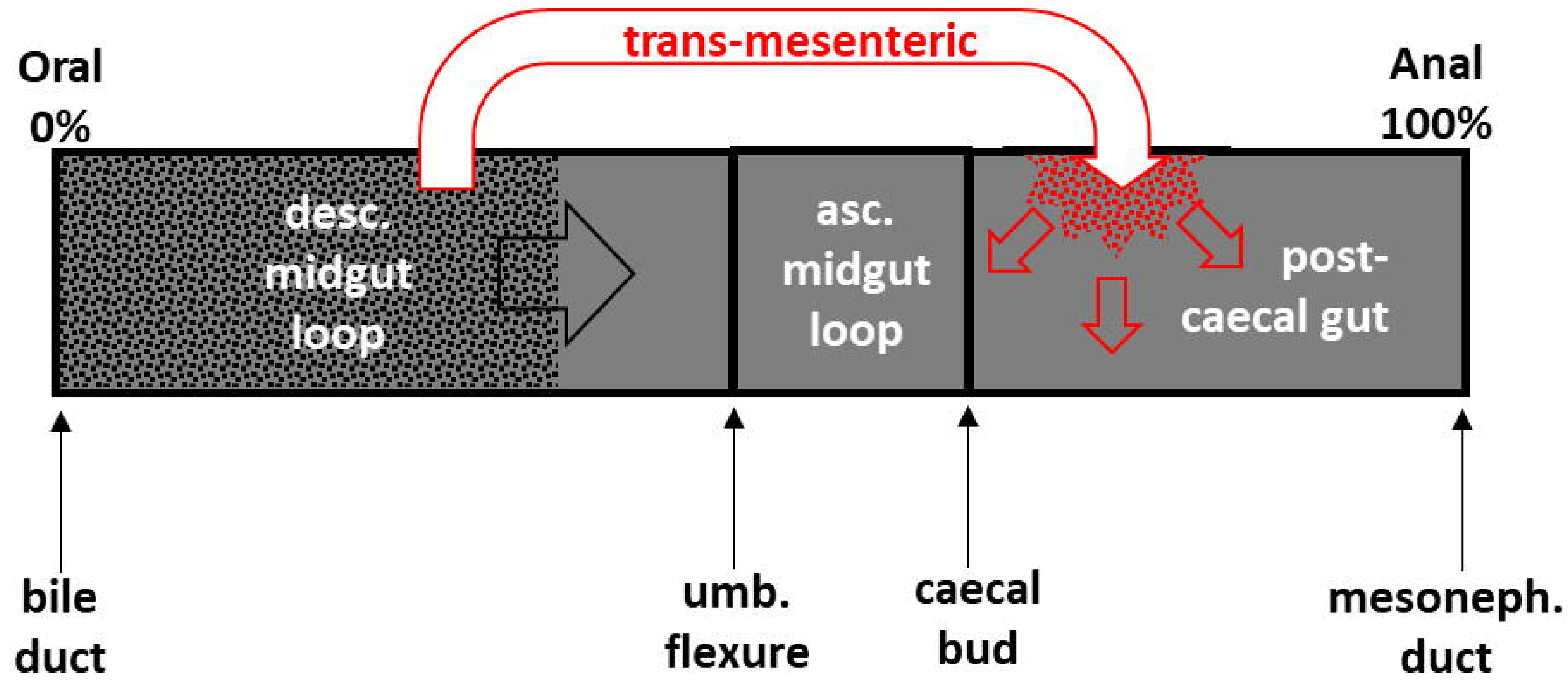

